\title{
Subcutaneous emphysema of the neck as a complication of high flow therapy in children: A case report
}

\author{
Luca Pierantoni, Arianna Dondi, Carlotta Biagi, Andrea Scozzarella, Federica Camela, \\ Marcello Lanari \\ Pediatric Emergency Unit, IRCCS Azienda Ospedaliero-Universitaria di Bologna, University of Bologna,
Bologna, Italy
}

\begin{abstract}
High Flow Nasal Cannula (HFNC) is a noninvasive technique for respiratory support increasingly used in the pediatric wards for the management of respiratory failure. Few data are reported about the safety of HFNC. We describe the case of a 3-months-old infant admitted for acute bronchiolitis Respiratory Syncyctial Virus-relat-
\end{abstract}

Correspondence: Arianna Dondi, Pediatric Emergency Unit, IRCCS Azienda Ospedaliero-Universitaria di Bologna, Sant'Orsola Hospital Via Massarenti 11, 40138 Bologna, Italy.

E-mail: arianna.dondi@gmail.com

Key words: Bronchiolitis; respiratory syncyctial virus (MeSH); respiratory therapy $(\mathrm{MeSH})$; mediastinal emphysema $(\mathrm{MeSH})$.

Contributions: LP provided direct care for the patient, drafted the initial manuscript, and reviewed and revised the manuscript. $\mathrm{AD}$ and $\mathrm{CB}$ provided direct care for the patient, provided substantial contribution for analysis and interpretation of data, and critically reviewed and revised the manuscript. FC and AS provided to collect data and drafted the manuscript. ML provided for the final revision of the manuscript. All authors approved the final manuscript as submitted and agree to be accountable for all aspects of the work.

Conflict of Interest: The authors declare no conflict of interest.

Availability of data and materials: All data underlying the findings are fully available.

Ethics approval and consent to participate: No ethical committee approval was required for this case report by the Department, because this article does not contain any studies with human participants or animals. Informed consent was obtained from the guardians of the patient included in this study.

Informed consent: Written informed consent was obtained from a legally authorized representative(s) for anonymized patient information to be published in this article.

Received for publication: 15 January 2021.

Revision received: 9 June 2021.

Accepted for publication: 15 June 2021

This work is licensed under a Creative Commons Attribution 4.0 License (by-nc 4.0).

C Copyright: the Author(s), 2021

Licensee PAGEPress, Italy

Emergency Care Journal 2021; 17:9615

doi:10.4081/ecj.2021.9615 ed and treated with HFNC for severe respiratory distress. Twelve hours after the beginning of HFNC a subcutaneous swelling of the neck, attributable to subcutaneous emphysema, became clinically evident. Radiological imaging showed pneumomediastinum with air leaking up to the neck. Patient was moved to PICU where he further worsened due to a mediastinal shift requiring drainage and mechanical ventilation. He was then progressively weaned from ventilation and was discharged from the hospital. Pneumomediastinum may occur during HFNC, particularly in moderate-severe cases of acute bronchiolitis. Patients undergoing HFNC should be strictly monitored in order to promptly recognize this complication and treat the child appropriately.

\section{Introduction}

Over the last decade, heated humidified High-Flow Nasal Cannula (HFNC) has become an increasingly used device for respiratory support in bronchiolitis, either alternative to traditional Low-Flow Nasal Cannula (LFNC) or to prevent more invasive methods such as continuous positive airways pressure and mechanical ventilation. It has been proved to be a well-tolerated non-invasive form of respiratory support, ${ }^{1}$ which is frequently administered in the general pediatrics ward. ${ }^{2}$

Despite the medical literature supports the use of HFNC in bronchiolitis, further evidence of its safety is required. ${ }^{3}$ The unpredictable rise in positive airways pressure during HFNC has been reported as a possible contributory factor in developing respiratory air leaks. ${ }^{4,5}$ Pneumomediastinum is a rare condition which occurs when air leaks into the mediastinum leading to chest pain, increased work of breathing and voice distortion, and requires prompt recognition and management. The diagnosis can be a challenge in bronchiolitis, due to the age of the patients and to the respiratory symptoms and deterioration that are common in the disease itself. To date, only few cases of air leak syndrome as a complication of HFNC have been reported in children. ${ }^{6}$

\section{Case Report}

A 3-month-old infant came to our hospital for acute bronchiolitis. He was born at 29 weeks of gestational age from twin pregnancy with a birth weight of $1380 \mathrm{~g}$; after birth, he was admitted to the neonatal intensive care unit where he underwent surfactant treatment for respiratory distress syndrome and nasal Continuous Positive Airways Pressure (CPAP) for 7 days. Respiratory Syncytial Virus (RSV) prophylaxis with Palivizumab was not administered because of his gestational age $>29$ weeks.?

At admission to our general pediatrics ward, the infant had fever and rhinitis, was mildly tachypnoic (50 breaths per minute) 
with no signs of respiratory distress and a normal peripheral oxygen saturation $\left(\mathrm{SpO}_{2}>92 \%\right)$, with only few bilateral crackles at chest auscultation. The day after, $\mathrm{SpO}_{2}$ fell to $88 \%$ and required oxygen supplementation with LFNC. Laboratory evaluation showed a White Blood Cell (WBC) count of 7,600/ $\mathrm{ml}^{3}$ (L 26\%, N $51 \%$ ) and C-Reactive Protein (CRP) was $0.34 \mathrm{mg} / \mathrm{dL}$; nasopharyngeal aspirate was negative for antigen detection of common respiratory viruses (RSV, metapneumovirus, influenza, parainfluenza, adenovirus) and Bordetella pertussis. Three days after admission we documented a further worsening of the respiratory pattern. Serum markers of bacterial infection still remained unchanged, and the chest X-ray showed multiple bilateral slight parenchymal consolidations, peripheral air trapping and a mild left pleural effusion. We decided to start High-Flow Nasal Cannula (HFNC), with an appropriate dimension thus not occluding more than $50 \%$ of his nares, at $21 / \mathrm{kg} / \mathrm{min}$, as suggested by international recommendations, ${ }^{8}$ and a $45 \%$ fraction of inspired oxygen was required to maintain an $\mathrm{SpO} 2$ over $92 \%$. Twelve hours later, a subcutaneous swelling of the neck became evident with snow crunching feeling at palpation, attributable to subcutaneous emphysema at first with no worsening of clinical conditions. Radiological imaging showed pneumomediastinum with air leaking back up to the neck (Figure 1). Therefore, he was moved to the Pediatric Intensive Care Unit (PICU), where he showed signs of respiratory distress like increased respiratory rate ( 95 breaths per minute), jugular retractions, and nasal flaring. Because of the occurrence of a tension pneumothorax with a mediastinal shift, the patient required pressure support ventilation and the placement of a pleural drainage. Furthermore, considering the marked bronchospasm and in the impossibility of delivering bronchodilators by aerosolization, he received endovenous bronchodilators, in particular aminophylline and magnesium sulphate, in addition to antibiotic therapy and parenteral nutrition. After 8 days, weaning with noninvasive mechanical ventilation was started and after 14 more days he was discharged from the PICU with complete clinical resolution. Home discharge was possible 25 days after admission.

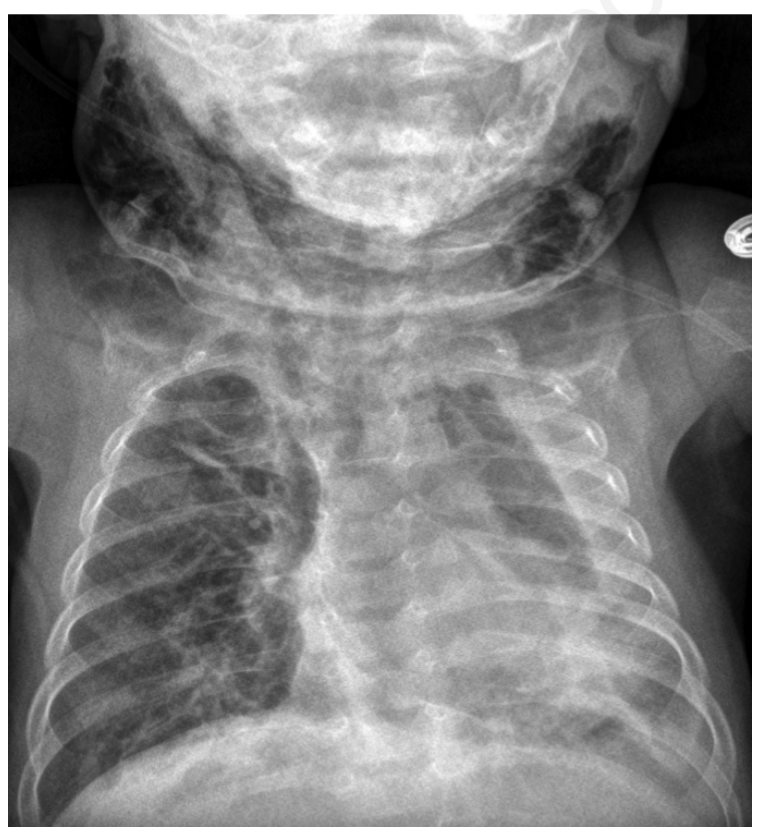

Figure 1. Pneumomediastinum and subcutaneous emphysema in the neck.

\section{Discussion}

Spontaneous air leak is a rarely described complication of bronchiolitis, due to the marked bronchiolar obstruction that heightens respiratory effort and intrapleural negative pressure; however, its real incidence remains unknown. ${ }^{9}$

The reported case suggests that HFNC might concur in the genesis of air leak syndromes especially if other risk factors for severe bronchiolitis, such as prematurity, are present. Among the few cases reported of air leak syndrome during HFNC, only one was a 2-month-old infant with bronchiolitis. ${ }^{6}$ Authors stated that high inspiratory volumes may have caused alveolar overdistention producing air leak syndromes. Though the pressure generated by HFNC in the distal airway is difficult to measure, it appears to be dependent on the size of the patient, the diameter of the nasal cannula compared to the nares and the flow rate. ${ }^{10}$ We suggest that other factors can be involved in overinflation, such as disease severity which can lead to increasing alveolar air trapping and a certain degree of bronchopulmonary dysplasia, related to the child's prematurity, even if it does not prevent the use of HFNC in this clinical setting. ${ }^{11}$ Considering the increasing evidence of efficacy and use of HFNC, ${ }^{12,13}$ the clinical staff should strictly monitor the response to HFNC therapy especially for patients with severe bronchiolitis or with other risk factors. Subcutaneous emphysema as a sign of occult pneumomediastinum is a clinical indicator that must be early recognized to promptly consider the opportunity to move the child to a higher intensity care level for the best respiratory management and treatment.

\section{Conclusions}

Pneumomediastinum may occur during HFNC, particularly in moderate and severe cases of acute bronchiolitis. Clinical staff should screen the onset of subcutaneous emphysema of the neck as a possible early sign of occult pneumomediastinum, to recognize this serious complication and provide adequate monitoring and treatment.

\section{References}

1. McKiernan C, Chua LC, Visintainer PF, Holley A. High flow nasal cannulae therapy in infants with bronchiolitis. J Pediatr 2010;156:634-8.

2. Bressan S, Balzani M, Krauss B, et al. High-flow nasal cannula oxygen for bronchiolitis in a pediatric ward: A pilot study. Eur J Pediatr 2013;172:1649-56.

3. Von S, Beggs S, Wong ZH, et al. High-flow nasal cannula therapy for infants with bronchiolitis. Cochrane Database Syst Rev 2014;1:CD009609.

4. Mikalsen IB, Davis P, Øymar K. High flow nasal cannula in children: a literature review. Scand J Trauma Resusc Emerg Med 2016;24:93.

5. Hutchings F, Hilliard TN, Davis PJ. Heated humidified highflow nasal cannula therapy in children. Arch Dis Child 2014:15.

6. Hegde S, Prodhan P. Serious air leak syndrome complicating high-flow nasal cannula therapy: a report of 3 cases. Pediatrics 2013;131:e939-44.

7. Ralston SL, Lieberthal AS, Meissner HC, et al. Clinical practice guideline: the diagnosis, management, and prevention of 
bronchiolitis. Pediatrics 2014;134:e1474-502. Erratum in: Pediatrics 2015;136:782.

8. Mayfield S, Jauncey-Cooke J, Hough JL, et al. High-flow nasal cannula therapy for respiratory support in children. Cochrane Database Syst Rev 2014;2014:CD009850.

9. Silva C, Almeida AF, Ferraz C, et al. Spontaneous pneumothorax with subcutaneous emphysema: a rare complication of respiratory syncytial virus infection. J Clin Med Res 2016;8:260-2.

10. Hasan RA, Habib RH. Effects of flow rate and airleak at the nares and mouth opening on positive distending pressure delivery using commercially available high-flow nasal cannula sys- tems: a lung model study. Pediatr Crit Care Med 2011;12:e2933.

11. Wilkinson D, Andersen C, O'Donnel CP, et al. High flow nasal cannula for respiratory support in preterm infants. Cochrane Database Syst Rev 2016;2:CD006405

12. Kepreotes E, Whitehead B, Attia J, et al. High-flow warm humidified oxygen versus standard low-flow nasal cannula oxygen for moderate bronchiolitis (HFWHO RCT): an open, phase 4, randomised controlled trial. Lancet 2017;389:930-9.

13. Franklin D, Babl FE, Schlapbach LJ, et al. A randomized trial of high-flow oxygen therapy in infants with bronchiolitis. N Engl J Med 2018;378:1121-31. 